\title{
Classical Methods of Tissue Studies: The Artifacts and the Impact of Transverse Serial Sections
}

\author{
DEH Zhou Patricia ${ }^{1,}$, Koffi DP ${ }^{2}$, Atto $V^{3}$, Monteomo GF ${ }^{4}$ \\ ${ }^{1}$ Laboratory of Histology-Embryology-Cytogenetic, UFR-Medical Sciences-University Felix Houphouēt-Boigny, Abidjan, Côte d'Ivoire \\ ${ }^{2}$ Department of Endocrinology-Diabetology, University Teaching Hospital of Yopougon, Abidjan, Côte d'Ivoire \\ ${ }^{3}$ Laboratory of Animal Physiology, UFR-Biosciences-University Felix Houphouēt-Boigny, Abidjan, Côte d'Ivoire \\ ${ }^{4}$ Laboratory of Animal Physiology, Pharmacology-Pharmacopoeia, UFR-Nature Science-University Nangui-Abrogoua, Abidjan, Côte \\ d'Ivoire
}

Email address:

dehzpatricia@yahoo.fr (DEH Z. Patricia)

${ }^{*}$ Corresponding author

\section{To cite this article:}

DEH Zhou Patricia, Koffi DP, Atto V, Monteomo GF. Classical Methods of Tissue Studies: The Artifacts and the Impact of Transverse Serial Sections. Biomedical Sciences. Vol. 3, No. 3, 2017, pp. 63-66. doi: 10.11648/j.bs.20170303.12

Received: May 26, 2017; Accepted: July 19, 2017; Published: August 9, 2017

\begin{abstract}
This work aims to study the mechanism of appearance of the histological alterations inherent in classical methods of tissue study and to give the difficulties related to the incidence of transverse serial sections. 4 lefts and rights testes were taken from two immature rats aged between 11 and 12 days. The testes were taken under anesthesia by ether inhalation. The gonads were fixed in 10\% formic aldehyde and dehydrated in alcohol and then included in the paraffin. The ribbon of transverse serial sections of $5 \mu \mathrm{m}$ were made by a microtome from the upper pole to the lower pole of the testes. The portions of the ribbon were then spread on slides. The smears were stained with hemalun-eosin and then covered with coverslip. The observation of transverse serial sections presented different types of degradation on them caused by technology. This involves deforming the contours of sections characterized by dye deposits, albuginea folds, tearing or destruction of the seminiferous tubes and then the formation of artificial vacuum between the tubes in the testicular parenchyma. It resulted from the stage of section, the loss of the three-dimensional (3D) coherence of the testes, generating the images visualized in a plan in a twodimensional (2D) plane resulting from the serial histological sections. The results of this study show that the steps of the methods of tissue study are major factors that can condition the success or failure of reading the results of the histological technique. This study invites us to consider artefacts that combine artificial images created by classical methods of tissue study. In addition, images visualized in a plan with two dimensions (2D) do not allow a direct assessment of the spatial configuration. Thus, a better understanding of the structures, a correction of deformities and a three-dimensional reconstitution (3D) could improve compliance.
\end{abstract}

Keywords: Artefacts, Serial Sections, Incidence of the Sections, Optical Microscope, Wistar Rats

\section{Introduction}

Histology refers to the study of biological tissues on a microscopic level. It makes it possible to understand their normal or pathological functioning [1].

The conventional methods of tissue studies are aimed at obtaining fine and transparent histological cuts that can be observed by an optical microscope.

They are based on tissue samples that can come from any part of the body. These biopsy tissue on living or necropsies on the non-living. In all histological operation, good preservation of tissue and/or cellular constituents remains essential [2, 3].

Histology is used in particular for diagnosis in the field of anatomy and pathological cytology [4]. In the course of research, the study can be done on an entire organ. This is the case of a preliminary study of the three-dimensional reconstruction of the intragonadic pathway of the testicular artery in the Wistar immature rat [5] from testicular cups subjected to the classic histological treatment. The images obtained from the histological sections were handled by 
computer graphics software. The results revealed that the testicular artery perforated the testis by the upper pole. It then divided into two terminal branches. In terms of health, the anatomical details provided by this study call for strict compliance with the testicular artery during surgery of the spermatic cord or its environment.

However, difficulties were encountered during the interpretation of the images of serological histological sections. These are the artefacts and the evaluation of structures from 2D images $[6,7,8]$. The artifacts are particularly used to identify certain types of picture degradation, usually directly related to the type of technique used in the preparation of histological sections $[6,9,10]$.

Artifacts are natural or artificial phenomena encountered during an observation or experiment $[6,9]$.

This term is used for the signatory certain types of image degradation, general in direct relation to the type of technique used during the preparation of the histological sections. Studies reported the artefacts or artificial images created by classical methods of tissue studies $[6,9,10]$.

The purpose of this work is to study the mechanism of appearance of the histological alterations inherent in classical methods of tissue study and to give the difficulties related to the incidence of histological serial sections.

\section{Material and Methods}

\subsection{Biological Material}

The biological material involved 4 testes (left and right) of 2 immature Wistar rat aged 11 and 12 days (UFR Biosciences animal facility, Félix Houphouet-Boigny University, AbidjanCôte d'Ivoire).

\subsection{Sample}

The dissection was performed under general anesthesia with ether by inhalation under a bell. The right and left epididymotesticular blocks were taken after an inguinal incision; the epididymis used to orient the testicle.

Each time you receive an information sheet on the following information: rat identification number, rat age and time of collection.

\subsection{Histological Technique}

Fixing: The collected gonads were fixed in $10 \%$ formalin for 72 hours.

After fixing: The gonads have been dehydrated in increasing concentrations of alcohol baths $(70 \%, 95 \%, 100 \%)$, clarification in toluene, impregnation and inclusion in paraffin (melting point: $55-57^{\circ} \mathrm{C}$ ). $5 \mu \mathrm{m}$ thick transverse serial strips were made by a paraffin microtome (Leica) from the upper pole to the lower pole of the testis. The ribbon portions were then spread on object slides (76 x 26mm, Fisher), where each cut was numbered. Hydration was carried out in three alcohol baths of decreasing degrees $(100 \%, 90 \%$ and $70 \%)$ followed by washing with distilled water.

Staining of haemalun-eosin sections
The histological sections were stained with hemalun-eosin for 5 minutes. They were then rinsed with running water and then immersed in the $1 \%$ eosin solution for 7 minutes. They were finally rinsed with running water.

Dehydration and assembly

Immediately after staining, the slides are soaked in three baths of absolute alcohol and then in two baths of toluene. The assembly was made between blade and slat with Eukit $[11,12]$.

\subsection{Optical Microscope Observation and Photo Taking}

The observation of the sections was carried out under an optical microscope. Microphotographs were taken using a digital camera (Canon 12 Megapixels).

\section{Results}

The results focused on the observation, various degradation of serial histological sections of the testes.

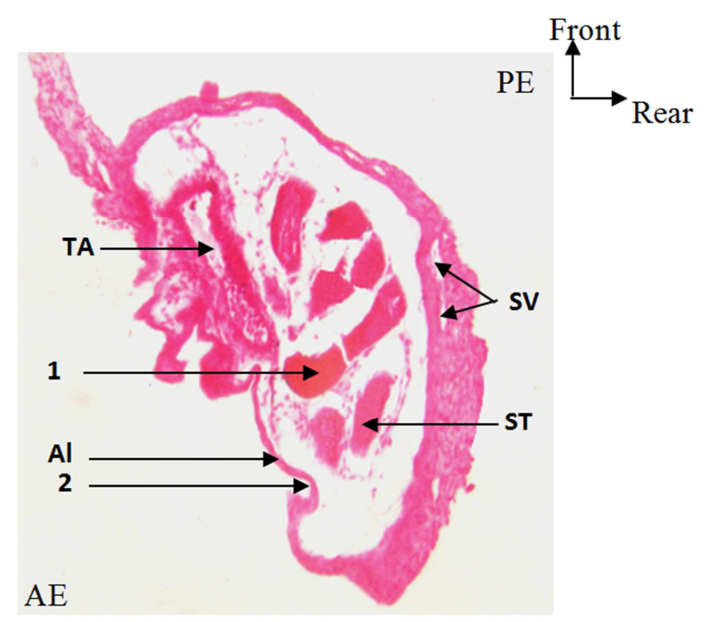

Figure 1. Transverse histological section of the higher pole of the testis of 11 days old little rat. (Hemalun-eosin; OM X 25). Testicular Artery (TA), Albugineous (Al), Seminiferous Tube (ST), Posterior Edge (PE), Anterior Edge (AE). Histological deteriorations: $(1)=$ Deposit of dye, $(2)=$ Folds of the albugineous.

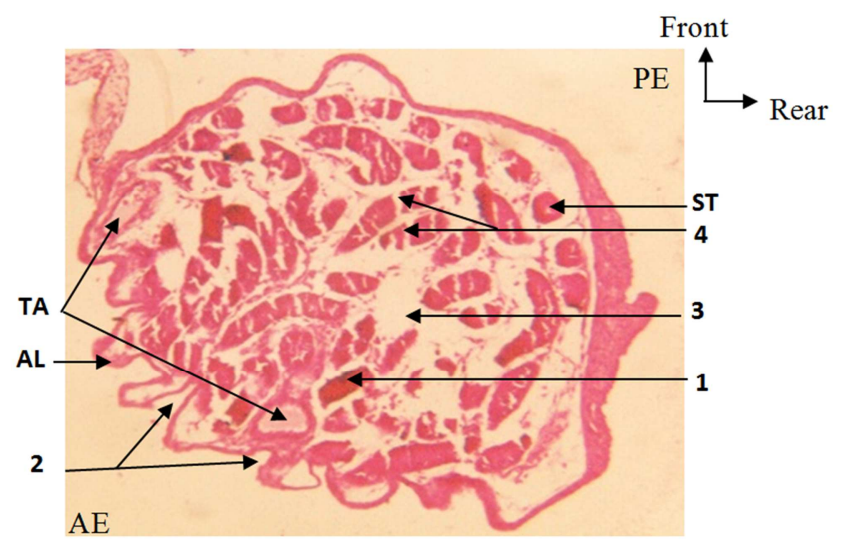

Figure 2. Transverse histological section of the upper pole of the testis of 12 days old little rat. (Hemalun-eosin; OM X 25). Testicular Artery (TA), Albugineous (Al), Seminiferous Tube (ST). Histological deteriorations: (1) = Deposit of dye. (2) = Folds of the albugineous. 


\section{Discussion}

This work showed histological alterations inherent in the classical study methods of the tissue and the difficulties related to the incidence of testicular sections.

Several types of degradation or alterations were observed in the histological sections. It's were the dye deposits, the deformation of the contours (folds of the albuginea), the destruction (tearing) of the seminiferous tubules and the formation of artificial vacuum in the testicular parenchyma (Figures 1 and 2).

From sampling of the testes to observation, there are many technical steps that are likely to generate these alterations.

In the course of our study, the testes were collected as soon as possible after the animal was sacrificed and alterations due to the sample occurred. These deformations which concern the testicle before the cut are global deformations. It could be an overall contraction of the testis due to mechanical effects (manipulation of the testis with pliers and scissors).

The gonads were immediately carried in a sufficient quantity of $10 \%$ saline formalin for fixation $[8,13]$. The latter was carried out to avoid post-mortem decomposition. The fixing defects such as retraction, could be explained by the fact that the formaldehyde contains non-coagulants making gradual fixing parts [6]. In addition, the quality of fixation with formalin is often considered to be mediocre for certain tissues, such as muscle, bone and testis, whose architecture often appears to be altered after cutting [14]. This disadvantage has also been observed in the case of the immature rat's testes (Figures 1 and 2). Unlike formaldehyde, Bouin's liquid is a fixative which contains coagulating agents allowing quick fixing of the parts, which explains the speed of obtaining a good consistency of samples observed in some works [15].

The alcohol was chosen for dehydration because it is a water-miscible reagent and miscible with the inclusion medium which is paraffin. Dehydration is pre-requisite for the fabric to be impregnated and included in a non-aqueous medium such as paraffin. It causes a diffusion of the lipids in the absolute alcohols, as well as a dissolution of the watersoluble proteins in the baths of alcohol of small percentages. This extraction will also produce a tissue retraction [6] as indicated in the previous paragraph with the use of formalin.

Concerning the clarification, it consisted in replacing the dehydration solution with a miscible solvent in the inclusion medium. This transition step was carried out by a hydrocarbon such as toluene. It induces a shrinkage more or less significant and extracts the residual tissue lipids that have not been by dehydration solution. A clarification of poor quality is the consequence of incomplete dehydration; this defect reveals whitish spots [16] which we had not observed in our testicular samples.

The impregnation filled the tissue cavities with a soluble product in the hot state and solid in the cold state. This is paraffin. The heat-inducing artifacts distortion and shrinkage, it is best not to leave the room stay too long in the molten paraffin [16].

So, it's necessary to note that an effective impregnation, is dependent on previous both stages (dehydration and clarification). A poorly dehydrated sample won't be totally cleared up and will be poorly impregnated with paraffin [16].

The inclusion thus provided an external support (paraffin block) to the testicular tissue, which allowed the cuts to be made. This step was carried out by pouring liquid paraffin into the bottom of the metal molds. The samples already impregnated were placed and oriented in these molds according to the direction of the serial sections that is to say from the head towards the tail of the epididymis. The whole thing was cooled in the open air. After cooling, the blocks of solid paraffin obtained are turned out [15]. A major difficulty of this step is the appearance of artificial vacuum in observation (Figure 2) due to the retraction of cells or tissues.

The main setbacks of shrinkage or potential distortion of tissues due to passage tissue samples in solutions (formalin, alcohol and toluene) may be responsible for the formation of folds in histological sections. Theses folds affected particularly tubular, circular and fibrous structures [9] as it was found in our study (Figures 1 and 2).

In this work, the coloring made it possible to highlight the different tissue elements and to differentiate between them. Hemalun-eosin staining showed the entire structure of the testes (Figures 1 and 2), with one dominant color (pinkish). This coloration is designed to demonstrate the general architecture of the cell, namely nuclei, cytoplasm and collagen fibers [16]. It is a routine coloration most commonly practiced, given its simplicity in the use and the speed of its realization. According to Exbrayat [17], the well-contrasted colors facilitate the immediate identification of the different tissues. However, alterations due to coloration may present dye deposits (Figures 1 and 2).

In addition, the testis was cut into slices of small thickness (about 5 microns) to obtain a set of 2D serial sections. From this stage of cutting of the testis, degradations resulted in histological sections. These are due to the striations of the microtome blade causing shear and tearing. Other causes have also been stated in the literature. Bacterial contamination during sampling, blunt disposable blades, cutting speed would be responsible [9]. To this, must be added the fragility of the testes in little rats, which have not resisted the pressure of the microtome blade. This, despite the inclusion of tissue that was previously practiced cutting.

The assembly on glass slides was done avoiding alterations of assembly (air bubbles between the blade and the lamella).

Regarding the impact of the cuts, transverse serial sections were performed on paraffin microtome. In the paraffin block, each collected serial section is welded to the previous one. It resulted from this stage of cutting, the loss of threedimensional coherence. Although the serial sections facilitate the in-depth study of an organ, topographic observation from these two-dimensional (2D) histological sections [5, 18, 19] did not allow a direct appreciation of its spatial configuration with a collection of plane images. At this stage, the perception of a three-dimensional (3D) organization could only result from a mental representation integrating all the information extracted to serial sections of the plane images. 
For a proper evaluation, it becomes necessary to use a true three-dimensional representation. Indeed, the threedimensional reconstruction (3D) has a realistic view of histological elements after reintroduced, the third dimension of the space, separated to the organs analyzed during serial cuts. It thus gives the possibility of comprehension inaccessible to the classical histological approaches and fills the needs of precision in the framework of the threedimensional microscopic morphology $[5,7,8]$.

To reduce the histological alterations observed in this work during sampling, organ manipulation should be avoided and tissues should not be exposed to mediocre fixers [6]. The fixation by infusion, made it possible to improve the quality of conservation of the constituents (the proteins in particular) $[20,21]$. It's important to quickly perform dehydration because too long a stay in alcohol give too pale [9].

A damaged microtome blade must be replaced because it won't produce good cuts and a reduction in the cutting speed of the microtome is required. The use of the cryostat, a cutting device suitable for small organs such as the brain of rodents [22] or the testes of immature rats would be possible.

Deformations should be taken into account and corrected to allow reconstruction of a $3 \mathrm{D}$ volume from $2 \mathrm{D}$ sections $[5,7,8]$ because each deformation of the histological sections is a difficulty for the $3 \mathrm{D}$ reconstruction.

\section{Conclusion}

In short, the stages of the methods of studying the tissues are major factors which may influence the success or failure of reading the results of the histological technique.

From a methodological point of view, the results of this study shows the difficulties encountered during the interpretation of the images resulting from the presence of the artefacts and the incidence of the cut. This study invites to be wary of artefacts that combine the artificial images created by the histological technique (alterations of the tissues).

In addition, images displayed in a two-dimensional plane (2D) do not allow a direct assessment of the spatial configuration. Thus, a better understanding of the structures, correction of deformities and a three-dimensional reconstitution (3D) could improve compliance.

\section{References}

[1] Anderson R. The importance of a histological diagnosis. Intern Med J, 2012; 42(4): 478.

[2] Jain N. Essentials before sending biopsy specimens: A surgeon's prespective and pathologists concern. J Maxillofac Oral Surg, 2011; 10(4): 361-364.

[3] Grove C, Oliver Peschel O and Nerlich AG. A systematic approach to the application of solf tissue histopathology in paleopathology. Bio Med Res Inter, 2015; (2015): 1- 9.

[4] Alturkistani HA, Tashkandi FM and Mohammedsaleh ZM. Histological stains: A literature review and case study. Glob J Health Sci, 2016; 8(3): 72-79.
[5] Deh ZP. Trajet de la branche intratesticulaire de l'artère spermatique chez le raton: Mise au point d'un modèle d'étude tridimensionnelle à Abidjan. [Mémoire: Diplôme d'Etudes Approfondies]. Abidjan: UFR-Sc Méd Univ FHB, 2007; 1526: 80p.

[6] Cannet C. Artéfacts. Les difficultés de la technique histologique. Les gageures de la fixation. Rev Fr Histotechnol, 2004; 17(1): 11-20.

[7] Tré-Yavo M, Deh ZP, Kokoua A, Yao GV, Ehouman A. Morphologie des artères intratesticulaires: Essai de reconstruction $3 \mathrm{D}$ à partir de coupes histologiques sériées chez le rat. JAMO, 2013; 7(2): 16- 21.

[8] Deh ZP. Trajet intragonadique de l'artère testiculaire: Approches histologique et tridimensionnelle chez le rat. [Thèse Unique]. Abidjan: UFR-Sc Méd Univ FHB, 2014; 26: 163p.

[9] Cannet C. Artéfacts. Les difficultés de la technique histologique de la circulation à la coupe. Rev Fr Histotechnol, 2006a; 19(1): 71-83.

[10] Chatterjee S. Artefacts in histopathology. J Oral Maxillofac Pathol, 2014; 18 (Suppl 1): S111-S116.

[11] Martoja R, Martoja M. Initiation aux techniques de l'histologie animale. Edit: Masson, 1967; 345p

[12] Furukawa S, Kuroda Y and Sugiyama A. A comparison of the histological structure of the placenta in experimental animals. Toxicol Pathol, 2014; 27(1): 11-18.

[13] Lulimann-Rauch R. Structure histologique du testicule, Edit: De Boeck Université- Paris, 2008; 704p.

[14] Larcher T. Evaluation de trois substances du formol sur la fixation des tissus biologiques d'animaux. Rev $\mathrm{Fr}$ Histotechnol, 2010; 23(1): 11-24.

[15] Djoudad-Kadji H, Benslimane S, Chevalier C, Kadji B, Exbrayat JM et Iguer-Ouada M. Visualisation des coupes histologiques des follicules ovariens de Barbus callensis, variation de fixateurs et de colorants. Rev Fr Histotechnol, 2011; 24(1): 21-28.

[16] Cannet C. Artéfacts. Les colorations topographiques. Rev Fr Histotechnol, 2006b; 19(1): 85-96.

[17] Exbrayat JM. Méthodes classiques de visualisation du génome en microscopie photonique. Ed. Tec-Doc Lavoisier, 2000; 182p.

[18] Tré-Yavo M. Vascularisation interne du testicule: Approches histologique et fonctionnelle chez le rat. [Thèse Unique]. Abidjan: UFR- Sc Méd Univ FHB, 2004; 2: 130p.

[19] Deh ZP, Tré-Yavo M, Kokoua A, Yao GV, Sakho SS. L'artère testiculaire: Etude du trajet intratesticulaire par des coupes transversales sériées chez le rat. JAMO, 2013; 7(1): 44- 49.

[20] Gage GJ, Kipke DR and Shain W. Whole animal perfusion fixation for rodents. J Vis Exp, 2012; (65): 3564.

[21] Soueid J, Nokkari A and Makoukji J. Techniques and methods of animal brain surgery: Perfusion, brain removal and histological techniques in: Kobeissy FH. Brain Neurotrauma: Molecular, neuropsychological and rehabilitation aspects. Editor. Boca Raton: CRC Press/Taylor \& Francis; 2015; Chapter 15; 725p.

[22] Dovero S. La coupe sous tous ses angles: L'univers de la microtomie. Rev Fr Histotechnol, 2010; 23(1): 33-44. 